\title{
Pesticide Resisdue Levels In Blood And Different Organs Of Pregnant Goat
}

\author{
${ }^{1,}$ K. Murali Mohan, ${ }^{2,}$ L. Ram Singh \\ ${ }^{1,2,}$ Department of Veterinary Gynaecology and Obstetrics, College of Veterinary Science, Rajendranagar, \\ Hyderabad - 500 030Sri Venkateswara Veterinary University, Tirupati, Andhra Pradesh. INDIA
}

\begin{abstract}
Eighteen Goats With One Month Pregnancy Were Randomly Divided Into Control, Untreated And Treated Groups. The Blood Samples From Control, Untreated And Treated Animals At 0 Month The Hexachlorocyclohexane (HCH) Residues Were In The Range Of 0.0002 To $0.0003 \mathrm{Mg} \mathrm{Kg}^{-1}$ And These Values Are Non Significant Within The Groups. The Average Levels Of HCH Residues In Blood Samples From Untreated Group Progressively Increased From 0.0003 At O Month To $0.0018 \mathrm{Mg} \mathrm{Kg}^{-1}$ At The End Of 3rd Month. Similarly The HCH Values From Treated Group Showed A Significant Increase From 0 To End Of 3rd Month With An Average Value Of 0.0002 To $0.0527 \mathrm{Mg} \mathrm{Kg}^{-1}$. Four Animals Of Treated Group Were Aborted In The Fourth Month Of The Experiment And The Average Concentration Of HCH Residues In Placenta Was $0.0122 \mathrm{Mg} \mathrm{Kg}^{-1}$. The Accumulation Of This Insecticide In Placenta Was About 22.2 Per Cent Of Maternal Blood. The Consumption Levels Of HCH In The Treated Group At 4.04 Mg/Kg/Day Was Much Higher Than The MRL And Affected The Gestation.
\end{abstract}

Key Words: Pregnant Does, HCH, Blood, Organs, HCH Residual Effect

\section{Introduction}

Goats roam more widely than other herbivores and meet their requirements from browsing on weeds neglected by others. In modern agriculture, pesticides have been recognized as an important factor in the production of crops. Indiscriminate use of pesticides in vegetable crops, their mishandling and negligence to follow proper waiting period, make marketed vegetables often contaminated with pesticides. Many samples were found to be contaminated with organochloride insecticides such as hexachlorocyclohexane (HCH), dichloro diphenyl trichloro ethane (DDT), aldrin etc. Among these the $\mathrm{HCH}$ concentration was highest. Regular consumption of the contaminated vegetable leaves, even though with lower concentration than maximum permitted levels, may lead to large bioaccumulation of the pesticides and thus pose a potential health hazard in animals. Research with chlorinated hydrocarbons demonstrated that these compounds can pass through the placenta and thus can cause abortion, stillbirths, birth defects etc. (Rumsey et al., 1973; Siddiqui et al., 1981

\section{Materials And Methods}

Eighteen non descript local goats of one month pregnancy were selected. The animals were randomly divided into three groups consisting of six animals each. Group I served as control group and were fed with standard feed consisting of concentrated mixture and green fodder. Group II served as untreated group in which the animals were similarly fed with the concentrates as in control, however the fodder was replaced with exfoliated cabbage leaves obtained from the local vegetable market of Hyderabad city. Group III animals served as treated groups fed with cabbage leaves similar to group II, however those were dusted with $\mathrm{HCH}$ (10\% dust) at the rate of $10 \mathrm{~g} / \mathrm{kg}$ of leaves using tiny hand duster prior to feeding adlibidum. The dusting of cabbage leaves with $\mathrm{HCH}$ at the rate of $10 \mathrm{~g} / \mathrm{kg}$ was based on the treatment of $\mathrm{HCH}$ as insecticide to the cabbage flower heads in field condition.

\section{Estimation Of Hch Residues From Blood And Other Organs}

The plasma was collected at 0 month, end of the first month, second month and third month from each animal from all three groups and stored at $-18^{\circ} \mathrm{C}$ till the estimation. Then the samples were subjected to extraction as per the procedure followed by Kapoor et al. (1981). 


\section{Estimation Of Hch Residues}

The $\mathrm{HCH}$ residues were estimated for the above samples by gas chromatography as per the procedure followed by Kapoor et al. (1981).

\section{Results And Discussion}

It is a common site that many goats seen picking vegetable wastes in the vegetable market yards. Usually the farmers use pesticides indiscriminately on vegetable crops and their mishandling and negligence to follow proper waiting period make marketed vegetables often contaminated with varied concentrations of pesticide residues. Agnihotri et al. (1974) who obtained vegetable samples from different markets of Delhi and found the residues of $\mathrm{BHC}$ as high as 50 parts per million (ppm) from 10 samples and further observed that about 25 per cent of the samples showed residues of DDT or BHC were either close to or much above the maximum residue limits (MRL) prescribed by FAO/WHO. Among the vegetables, cabbage and cauliflower showed higher levels of BHC. Khandekar et al. (1982) found 92 out of 311 samples to contain insecticide residues above the MRL in Mumbai vegetable markets. Similar studies were also made by Rup Lal et al. (1989) and observed in some vegetables, Lindane (Isomer of $\mathrm{HCH}$ ) levels to be above the maximum residue limits. The study is aimed to investigate the effect of insecticide contaminated feeds on reproductive system of goats. Since these treated cabbage leaves were fed to the group (treated animals), it is difficult to assess the individual intake of insecticides daily. However, considering the total consumption of cabbage leaves per day by the six animals in the group which is averaged as $14.4 \mathrm{~kg}$. It can be assumed that each animal consume $2.4 \mathrm{~kg}$ of cabbage leaves. Thus, the daily intake of $\mathrm{HCH}$ by each animal is about $49.3 \mathrm{mg}$. On body weight basis $(4.04 \mathrm{mg} / \mathrm{kg} / \mathrm{day})$ of insecticide. There are no studies to indicate LD50 values for $\mathrm{HCH}$ to the goats. The present consumption is lower by the goats when compared to the reported lethal dose of laboratory animals and dogs. For instance, Frank and Braun (1984) calculated a lethal dose of 13-16 mg kg${ }^{-1}$ of BHC for calves that died in 50 hours. In the present experiment the goats sustained much larger dose of $\mathrm{HCH}$ than the MRL of $0.25 \mathrm{mg} \mathrm{kg}^{-1}$ in feed and also for longer period. This may be due to the fact that the goats being ruminants, the pesticide ingested by them is well diluted with the rumen fluid and may significantly be modified due to the reduced $\mathrm{PH}$ of the rumen liquor. In most cases in the rumen the insecticides may have detoxified or altered in such a manner that may result in delayed absorption (Oehme and Barrett, 1986). Recovery percentages of pesticide from blood and other organs were comparable with other scientists (Barquet et al., 1981) who used gas chromatography (Table 1). HCH residues in blood samples were analysed from all the three groups (Table 2). Similarly both experimental groups i.e., untreated and treated groups showed $\mathrm{HCH}$ values at the 0 month comparable to control animals. The $\mathrm{HCH}$ residues in blood samples from untreated groups showed a significant rise from 0 month to third month of experimental period. The progressive increases in $\mathrm{HCH}$ residues indicate accumulation of the insecticides in the storage organs. Similar to our studies, Siddiqui et al. (1981) estimated HCH residues from large number of Indian women and found on an average the blood samples contained $0.022 \mathrm{mg} \mathrm{kg}^{-1}$ due to consumption of agrochemicals.

The effect of $\mathrm{HCH}$ residues in untreated group appeared to have no adverse effect on gestation. The prenatal growth is more or less directly related to the transport of various compounds across the placental barrier. It has been reported that uptake of aminoacids is inhibited by the presence of metabolic poisons (Joseph et al., 1968). The report of Courtney (1979) indicated that the long term consumption of food contaminated with pesticides might be associated with the still births. The $\mathrm{HCH}$ residues in blood samples from treated group showed a progressive significant rise from 0 month to third month (Table 2). In the available literature, there is no data on $\mathrm{HCH}$ residues from blood samples in animals that were subjected to longer periods of consumption of contaminated feed for comparison. In the present study attempts were made to correlate the HCH levels of the maternal blood to the levels in placenta which resulted in abortion. The correlation between maternal blood and in placenta indicated that on an average about 22.2 per cent of the maternal residues were accumulated in the placenta and resulted in abortion. O'Leary et al. (1970) compared the levels of DDT in maternal blood to umbilical cord blood and reported about 43 per cent of the maternal blood DDT residues was presented in the umbilical cord. Presence of organochlorinated compounds in human placenta of pregnant women have been linked with possible miscarriages, still births (Saxena et al., 1980 and ITRC, 1987). Similarly, several studies have also suggested evidences that organochlorine compounds act as antagonists to pregnancy, through spontaneous abortion, premature or still born deaths (ITRC, 1987). The present study suggest that similar to the reports from other market yards, the exfoliated leaves of the cabbage is also considerably contaminated with the $\mathrm{HCH}$ pesticides and prolonged feeding of these contaminated leaves, appears to have deleterious effects on reproduction as this chemical has a tendency to store in different organs. 


\section{ACKNOWLEDGEMENTS}

The authors are highly thankful to the Acharya N.G. Ranga Agricultural University, Hyderabad, India for extending facilities to work on pesticides.

\section{REFERENCES}

[1]. Agnihotri, N.P., Dewan, R.S. and Dixit, A.K . (1974). Indian J. Ento., 36: 1-4.

[2]. $\quad$ Barquet, A. et al. (1981). J. Toxicol. Environ. Health, 7: 469-479.

[3]. Courtney, K.D. (1979). Environmental Research, 20: 225-226.

[4]. Davidow, B. and Frawley, J.P. (1951). Proceedings of the Society for Experimental Biology and Medicine, 76: 780-783.

[5]. Frank, R. and Braun, H.E. (1984). Bulletin of Environmental Contamination and Toxicology, 32: $533-536$.

[6]. I.T.R.C. (1987). Status Report on pesticide residues, Department of Science and Technology, Government of India, New Delhi p.12.

[7]. Joseph, D. et al. (1968). Am. J. Obst. and Gynaec., 101: 820-829.

[8]. Kapoor, S.K., et al. (1981). J. Assoc. Official Analytical Chemists, 64: p.14-15.

[9]. Khandekar, S.S. et al. (1982). Environmental Pollution, B4: 127-134.

[10]. Narsimha Rao, B. (1994). Pesticide Contamination Bulletin. AICRP on pesticide residues, College of Agriculture, Andhra Pradesh Agricultural University, Rajendranagar, Hyderabad p.4.

[11]. Oehme, F.W. and Barrett, D.S. (1986). Veterinary Gastrointestinal Toxicology. In "Veterinary Clinical Toxicology", University of Sydney, Sydney, Australia pp.509-519.

[12]. O'Leary, et al. (1970). Am. J. Obst. and Gynaec., 107: 65-68.

[13]. Oshiba, K. (1972). J. Osaka City Med. Cent., 21: 1-9.

[14]. Oshiba, K. and Kawakita, H. (1972). J. Food Hygiene Society, Japan 13: 184-188.

[15]. Rumsey, T.S. et al. (1973). J. Anim. Sci., 37: 1186-1190.

[16]. Rup Lal. et al. (1989). Bulletin of Environmental Contamination and Toxicology, 42: 45-49.

[17]. Saxena, M.C. et al. (1980). Toxicology, 17: 323-331.

[18]. Siddiqui, M.K.J. et al. (1981). Environ. Res., 24: 24-32.

Table 1. Recovery percentage of $\mathrm{HCH}$ in different organs.

\begin{tabular}{|c|l|c|c|c|c|}
\hline S.No. & Organs & $\alpha$ & $\beta$ & $\gamma$ & $\delta$ \\
\hline 1 & Blood & 85.5 & 92.3 & 98.5 & 94.5 \\
\hline 2 & Heart & 89.5 & 88.5 & 91.2 & 89.0 \\
\hline 3 & Lungs & 87.6 & 83.2 & 93.5 & 81.5 \\
\hline 4 & Stomach & 78.5 & 88.5 & 90.5 & 89.0 \\
\hline 5 & Placenta & 85.5 & 92.0 & 98.5 & 95.0 \\
\hline 6 & Fat & 86.5 & 99.5 & 98.0 & 95.0 \\
\hline 7 & Liver & 82.5 & 90.5 & 89.2 & 81.5 \\
\hline 8 & Kidney & 81.5 & 82.5 & 89.2 & 78.5 \\
\hline
\end{tabular}

Table 2. Accumulation of $\mathrm{HCH}$ residues (mg kg-1) in blood samples from different group.

\begin{tabular}{|c|c|c|c|c|}
\hline Group & 0 month & $1^{\text {st }}$ month & $2^{\text {nd }}$ month & $3^{\text {rd }}$ month \\
\hline Control & $\begin{array}{l}0.0002^{\mathrm{a}} \\
\pm 0.00003\end{array}$ & $\begin{array}{l}0.0002^{\mathrm{a}} \\
\pm 0.00002\end{array}$ & $\begin{array}{l}0.0003^{\mathrm{a}} \\
\pm 0.00003\end{array}$ & $\begin{array}{l}0.0002^{\mathrm{a}} \\
\pm 0.00003\end{array}$ \\
\hline Untreated & $\begin{array}{l}0.0003^{\mathrm{a}} \\
\pm 0.00003\end{array}$ & $\begin{array}{l}0.0013^{\mathrm{b}} \\
\pm 0.00005\end{array}$ & $\begin{array}{l}0.0016^{\mathrm{b}} \\
\pm 0.00009\end{array}$ & $\begin{array}{l}0.0018^{\mathrm{b}} \\
\pm 0.00009\end{array}$ \\
\hline Treated & $\begin{array}{l}0.0002^{\mathrm{a}} \\
\pm 0.00003\end{array}$ & $\begin{array}{l}0.0174^{\mathrm{c}} \\
\pm 0.0001\end{array}$ & $\begin{array}{l}0.0459^{c} \\
\pm 0.0001\end{array}$ & $\begin{array}{l}0.0527^{\mathrm{c}} \\
\pm 0.0001\end{array}$ \\
\hline
\end{tabular}

Each value is an average of replicate sample.

Values bearing different superscript differ $(\mathrm{P}<0.05)$. 